\title{
International Journal of
}

\section{Clinical Obstetrics and Gynaecology}

ISSN (P): 2522-6614

ISSN (E): 2522-6622

(C) Gynaecology Journal

www.gynaecologyjournal.com

2021; 5(6): 43-45

Received: 04-09-2021

Accepted: 12-11-2021

Dr. Sangeeta Tengli

Assistant Professor, Department of

OBG, Bidar Institute of Medical

Sciences, Bidar, Karnataka, India

Dr. Uma B Deshmukh

Associate Professor, Department of

OBG, Bidar Institute of Medical

Sciences, Bidar, Karnataka, India

Corresponding Author:

Dr. Sangeeta Tengli

Assistant Professor, Department of

OBG, Bidar Institute of Medical

Sciences, Bidar, Karnataka, India

\section{Efficacy and satisfaction rate in postpartum intrauterine contraceptive device insertion: A prospective study}

\author{
Dr. Sangeeta Tengli and Dr. Uma B Deshmukh
}

DOI: https://doi.org/10.33545/gynae.2021.v5.16a.1056

\section{Abstract}

Background: Early resumption of sexual activity coupled with early and unpredictable ovulation leads to many unwanted pregnancies in the first year postpartum. Moreover, in developing countries particularly, women who once go back home after delivery do not return for even a routine postpartum check-up, leave aside contraception. There are many reasons for not using contraception, specifically long-acting reversible contraception (LARC), including lack of awareness, non-availability of accessible family planning services, social pressure, and limitations on women's mobility mostly due to cultural or geographical factors. Thus, immediate postpartum family planning services need to be emphasized wherein the woman leaves the hospital with effective contraception in place. This study puts in an effort to find the efficacy and satisfaction rate in postpartum intrauterine contraceptive device insertion.

Aims and Objectives: To determine the efficacy and satisfaction rate in postpartum intrauterine contraceptive device insertion.

Materials and Methods: IUCD was inserted immediately postpartum regardless of the mode of delivery either intra-cesarean section (CS) or spontaneous vaginal delivery (SVD).

Some patients took longer to make the decision, and IUCD was inserted after vaginal delivery within 48 hours. All the patients were followed up at six weeks and six months.

Results: There were some complications and as accepted the satisfaction levels were good in the cases who did not have any complications.

Conclusion: The satisfaction level is good except in the patients who suffer from initial complications

Keywords: Efficacy, satisfaction, post-partum, intra uterine, contraception

\section{Introduction}

Early resumption of sexual activity coupled with early and unpredictable ovulation leads to many unwanted pregnancies in the first year postpartum. Moreover, in developing countries particularly, women who once go back home after delivery do not return for even a routine postpartum check-up, leave aside contraception. There are many reasons for not using contraception, specifically long-acting reversible contraception (LARC), including lack of awareness, non-availability of accessible family planning services, social pressure, and limitations on women's mobility mostly due to cultural or geographical factors. Thus, immediate postpartum family planning services need to be emphasized wherein the woman leaves the hospital with effective contraception in place. Institutional deliveries create a unique opportunity to offer a long-acting yet reversible method of contraception to women immediately following their childbirth. Cochrane reviews provide evidence of the safety and feasibility of Long-acting reversible contraception insertions in various settings ${ }^{[1-2]}$. Initiation of family planning at the time of birth is opportune, since few women in lower source settings who give birth in a facility return for further care ${ }^{[3,4]}$. PPIUCD is an effective long-acting reversible contraceptive, which encourages women to give birth in health care facilities ${ }^{[5,6]}$. LARC has several advantages for use in the postpartum period as it is effective, coitus independent and does not interfere with breastfeeding. Effective intervention is required at an individual, interpersonal, community and institutional levels, and policymakers should play their role in providing affordable and easily accessible methods of contraceptive to improve maternal and child health. Provision of awareness and education about different methods of contraception during the antenatal and postnatal period reduce the rate of unplanned pregnancies. Healthcare professionals should be well trained for the appropriate insertion of IUCD in the postpartum period ${ }^{[7,8]}$. This study puts in an effort to find the efficacy and satisfaction rate in postpartum intrauterine contraceptive device insertion. 


\section{Aims and Objectives}

To determine the efficacy and satisfaction rate in postpartum intrauterine contraceptive device insertion.

\section{Materials and Methods}

This study was done in the Department of OBG, Bidar Institute of Medical Sciences Bidar.

The study was done Aug 2019 to Jan 2020.

IUCD was inserted immediately postpartum regardless of the mode of delivery either intra-cesarean section (CS) or spontaneous vaginal delivery (SVD).

Some patients took longer to make the decision, and IUCD was inserted after vaginal delivery within 48 hours.

All patients were asked to fill in a questionnaire based upon likerts scale to judge the satisfaction level. And there was one direct question at the end which asked about satisfaction. All the patients were followed up immediately, after a week, after a month, after 3 months and after 6 months.

\section{Results}

Table 1: Age

\begin{tabular}{|c|c|c|}
\hline Number & Mean age & Std. Deviation \\
\hline 30 & 23.21 & \pm 3.34 \\
\hline
\end{tabular}

Table 2: Complications

\begin{tabular}{|c|c|}
\hline Expulsion & 1 \\
\hline Secondary PPH & 1 \\
\hline Irregular bleeding & 3 \\
\hline Infection & 1 \\
\hline Shock & 1 \\
\hline
\end{tabular}

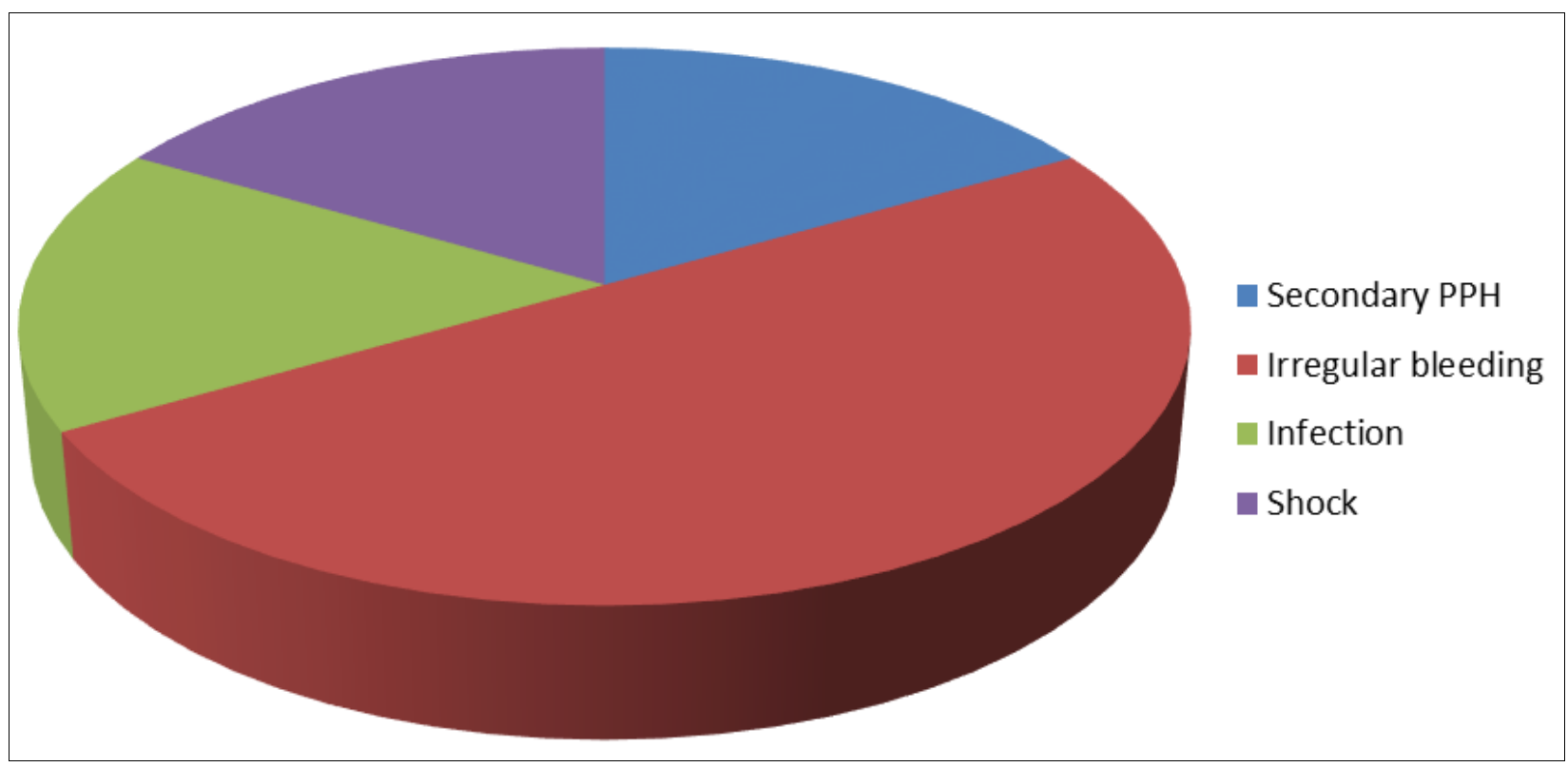

Graph 1: Complications

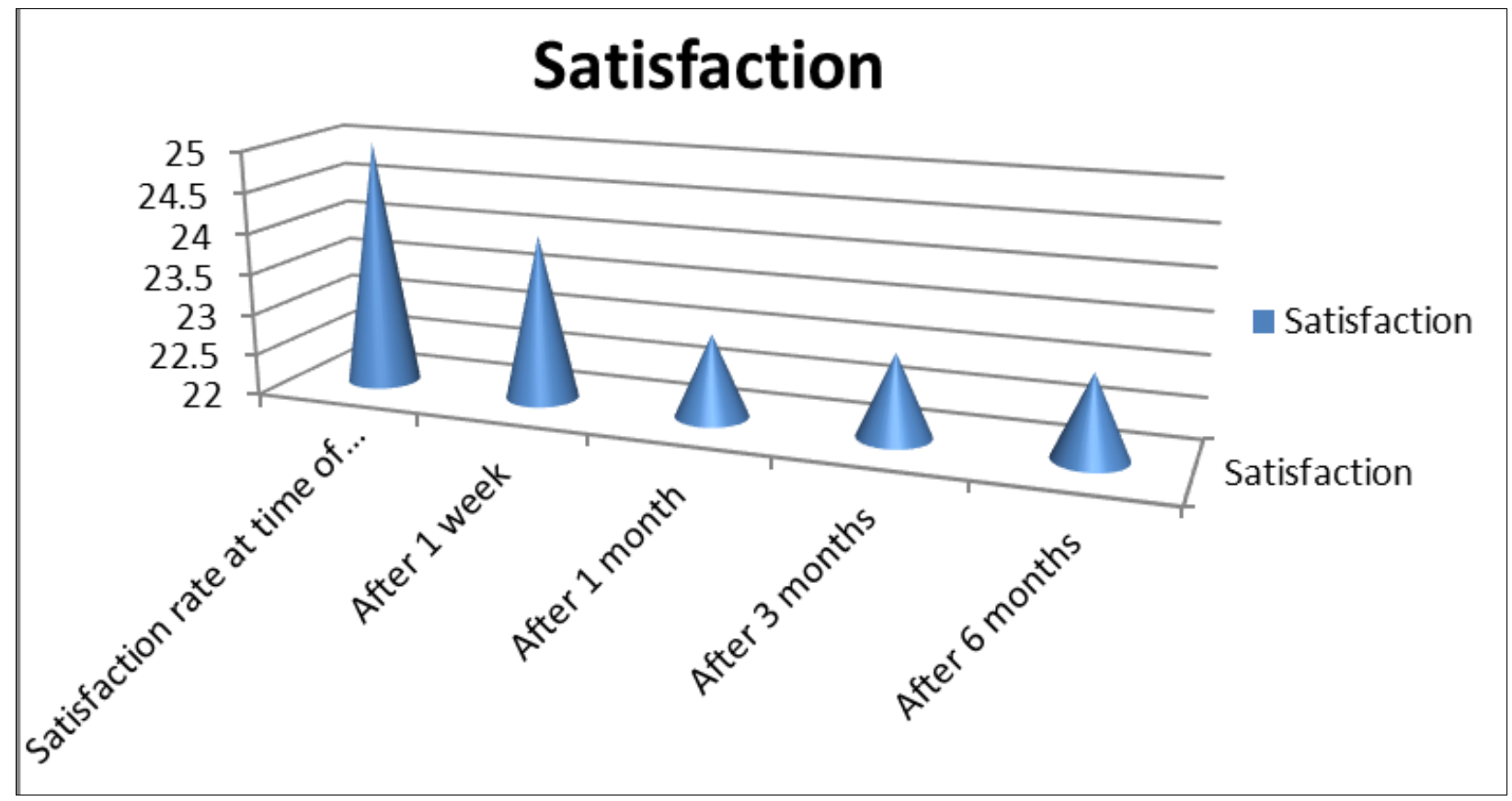

Graph 2: Satisfaction based on Likerts scale 


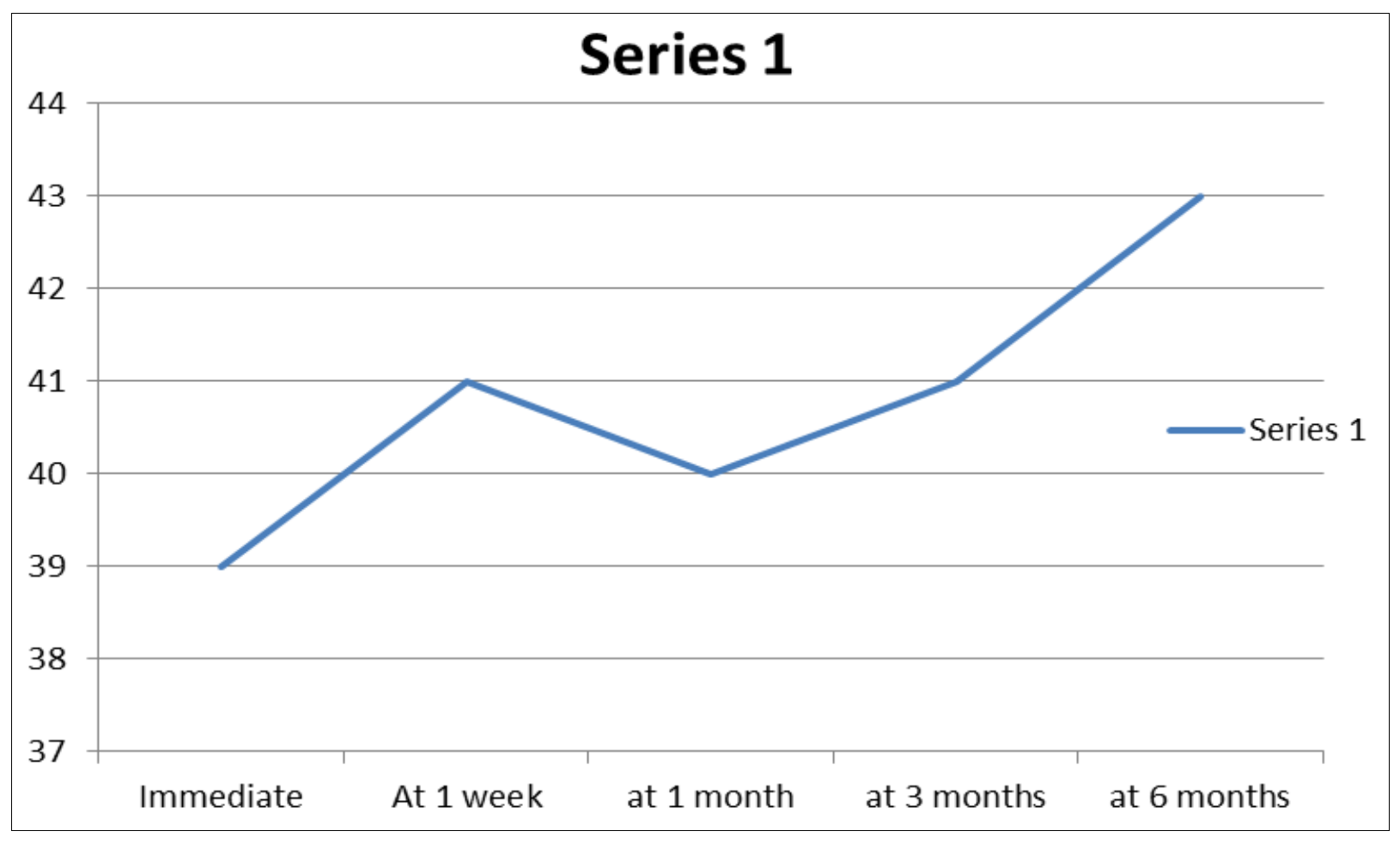

Graph 3: Satisfaction based on Likerts scale

\section{Discussion}

Postpartum family planning is the prevention of unintended and closely spaced pregnancies during the first 12 months following childbirth ${ }^{[9]}$. Unintended pregnancy is characterized by untimely and short pregnancy intervals and it can result in acute maternal complications and death of mothers and their children. In the United States, half of the pregnancies are unintended. According to "Healthy people 2020," almost 6.1 million pregnancies are unplanned and it has a direct association with negative health and economic outcomes ${ }^{[10]}$. An unplanned pregnancy can cause maternal and child morbidity and mortality. In a recent study of postpartum unintended pregnancies, $86 \%$ resulted from non-use of contraception and almost $50 \%$ ended in induced abortions ${ }^{9}$, ${ }^{10]}$. Using family planning (FP) to space births at least 36 months apart can avert $30 \%$ of maternal deaths and $10 \%$ of child deaths [3-4]. Insertion of an intrauterine contraceptive device (IUCD) immediately after delivery has been recommended by the World Health Organization (WHO), as one of the safe and effective methods of temporary contraception [11]. Postpartum intracontraceptive uterine device (PPIUCD) can be safely used in all breastfeeding women. Almost $39 \%$ to $65 \%$ of women in the first-year postpartum have an unmet need for family planning [11]. Hence, providing contraception in this sensitive period is important. PPIUCD reduces the rate of abortions and it is a costeffective, reversible, and convenient choice of contraception.

\section{Conclusion}

The satisfaction level is good except in the patients who suffer from initial complications. Steps are necessary to counsel the patients and take appropriate steps so as to reduce the complications.

\section{References}

1. Whiteman MK, Tyler CP, Folger SG, Gaffield ME, Curtis $\mathrm{KM}$. When can a woman have an intrauterine device inserted? A systematic review. Contraception 2013;87:666673. 10.1016/j.contraception.2012.08.015 2019 Iftikhar et al. Cureus 11(9), e5646. DOI 10.7759/cureus.5646 6 of 7.
2. Ross JA, Winfrey WL. Contraceptive use, intention to use and unmet need during the extended postpartum period. Int Fam Plan Perspect 2001;27:20-7. 10.2307/2673801.

3. Grimes D, Schulz K, Stanwood N Immediate post-partum insertion of intrauterine devices. Cochrane Database Syst Rev 2010;5:CD003036. 10.1002/14651858.CD003036.pub2.

4. Pfitzer A, Mackenzie D, Blanchard H. A facility birth can be the time to start family planning: postpartum intrauterine device experiences from six countries. Int J Gynaecol Obstet 2015;2:54-61. 10.1016/j.ijgo.2015.03.008.

5. Navodani KT, Fonseka P, Goonewardena CS. Postpartum family planning: missed opportunities across the continuum of care. Ceylon Med J 2017;2:87-91.

10.4038/cmj.v62i2.8472

6. https://www.healthypeople.gov/2020/topicsobjectives/topic/family-planning.

7. Huang YM, Merkatz R, Kang JZ. Postpartum unintended pregnancy and contraception practice among rural-tourban migrant women in Shanghai. Contraception 2012;86:731738. 10.1016/j.contraception.2012.05.007.

8. Report of a technical consultation on birth spacing 2005 . Accessed: September 2, 2019

https://www.who.int/maternal_child_adolescent/documents/ birth_spacing05/en/.

9. Programming strategies for postpartum family planning 2013. Accessed: September 2, 2019:

https://www.who.int/reproductivehealth/publications/family _planning/ppfp_strategies/en/

10. Black A, Guilbert E, Costescu D. Canadian contraception consensus. J Obstet Gynaecol Can 2015;37:936-938.

11. Cleland K, Zhu H, Goldstuck N, Cheng L, Trussell J. The efficacy of intrauterine devices for emergency contraception: a systematic review of 35 years of experience. Hum Reprod 2012;27:1994-2000. 10.1093/humrep/des140. 